\title{
A Rare Case of Drug-induced Eosinophilia Following Reintroduction of Clozapine
}

\author{
${ }^{1}$ Tanupreet Kaur, ${ }^{2}$ Harneet Kaur, ${ }^{3}$ Sakshi Gupta, ${ }^{4}$ Subhash Das
}

\section{ABSTRACT}

Clozapine, an atypical antipsychotic agent commonly used for treatment-resistant schizophrenia (TRS) is well known to cause blood dyscrasias among many other common side effects like sedation, sialorrhoea, weight gain and some rare side effects such as eosinophilia. Clozapine-induced eosinophilia though rare has received extensive attention and may preclude its use in the patients who may otherwise be responding well to the treatment. Although there has been evidence in the literature highlighting the rare presentation of eosinophilia in patients receiving clozapine. Here we present a rare case of undifferentiated schizophrenia who received clozapine in the past and tolerated it well but developed transient eosinophilia on its re-introduction.

Keywords: Clozapine, Eosinophilia, Schizophrenia.

How to cite this article: Kaur T, Kaur H, Gupta S, Das S. A Rare Case of Drug-induced Eosinophilia Following Reintroduction of Clozapine. Ind J Priv Psychiatry 2018;12(1):59-61.

\section{Source of support: Nil}

\section{Conflict of interest: None}

\section{INTRODUCTION}

Clozapine is used in TRS but often mandates intensive monitoring of side effects. Clozapine-induced eosinophilia though rare is seen in 1 to $2.2 \%$ of clozapinetreated patients mostly with a transient course and spontaneous remission. ${ }^{1,2}$ However, in few cases it has been reported to be a predictor of subsequent neutropenia, ${ }^{3}$ eosinophilic colitis, ${ }^{4}$ pancreatitis, and myocarditis. ${ }^{5}$ Although there are few case reports of eosinophilia developing during treatment with clozapine in patients who have schizophrenia. ${ }^{6-10}$ Here we present a rare case of schizophrenia who had received clozapine in the past without any significant event but developed transient eosinophilia during the initial weeks following its reintroduction.

\footnotetext{
1,2 Postgraduate Junior Resident, ${ }^{3}$ Senior Resident, ${ }^{4}$ Assistant Professor

1-4 Department of Psychiatry, Government Medical College and Hospital, Chandigarh, India
}

Corresponding Author: Sakshi Gupta, Senior Resident, Department of Psychiatry, Government Medical College and Hospital, Chandigarh, India, e-mail: dr.sakshi.Ih06@gmail.com

\section{CASE}

Mr R, 36 years, male, having undifferentiated schizophreniawith a total duration of illness of 17 years presented to the inpatient unit following a relapse. His treatment history revealed that he had responded to clozapine in the past but was non-compliant for the last 1.5 years. As there was a history of good response to clozapine in the past, it was decided by the treating team to re-start clozapine. Before starting clozapine, all the necessary investigations including complete hemogram, liver function tests (LFT), renal function tests (RFT), fasting blood glucose level and electrocardiogram (EC) were done which came out to be within normal limits except hemogram which revealed lower hemoglobin. His total leukocyte count (TLC) was $10,500 / \mathrm{mm}^{3}$ (normal range 4000 to $11000 /$ $\mathrm{mm}^{3}$ ), of which $7 \%$ leucocytes were eosinophils (normal range $<6 \%$ ). Treatment was started with clozapine $25 \mathrm{mg}$ /day along with diazepam $7.5 \mathrm{mg} /$ day for sleep disturbance. After one week of starting clozapine, i.e., on the 7th day, TLC counts raised to 16,000 / $\mathrm{mm}^{3}$, of which $8 \%$ leucocytes were eosinophils.No features of an allergic reaction such as rash were present. Following consultation with the medicine department, I/V antibiotics were addedbecause of the raised TLC count. As the patient was responding well to clozapine,its dosage was gradually increased up to $350 \mathrm{mg} /$ day. Subsequently, his total leukocyte count increased up to $18,100 / \mathrm{mm}^{3}$, out of which $23 \%$ leucocytes were eosinophils during the $3 \mathrm{rd}$ week. IgE levels were raised to $2,500 \mathrm{IU} / \mathrm{mL}(\mathrm{N}=30-300 \mathrm{IU} / \mathrm{mL})$. Because of the increased eosinophil count, he was investigated further on the lines of urine microscopic examination and culture and peripheral blood smear for malarial parasite. All reports were within normal limits. His chest X-ray was also normal. Pulmonary eosinophilia was ruled out. Hematology consultation was taken, and the patient was given albendazole empirically for one week. As his hemoglobin was also on the lower side, his serum iron was investigated, and the findings revealed serum iron $=17$ (low); total iron binding capacity $($ TIBC $)=350$ (high); unsaturatediron binding capacity $($ UBIC $)=333$; transferrin saturation $=4.8 \%$ (high); indicative of iron deficiency anemia. Even after completing albendazole- 
and antibiotic course for 1 week, his TLC was still 20,900/ $\mathrm{mm}^{3}$, out of which $40 \%$ were eosinophils. Thus treating team considered the possibility of clozapine-induced eosinophilia and therefore reduced his clozapine dose to $175 \mathrm{mg}$ /day and subsequently to $150 \mathrm{mg}$ /day after 3 days. The patient was monitored strictly for blood dyscrasias. His TLC count dropped to $8,700 / \mathrm{mm}^{3}$ and eosinophil count reduced to $20 \%$ (50\% reduction) after one week of decreasing the drug dosage. He continued to receive $150 \mathrm{mg} /$ day of clozapine. Iron supplementation was also given. As a result of his hemoglobin raised by 2 $\mathrm{gm} \%$ in one week. The patient was discharged on clozapine $150 \mathrm{mg} /$ day and trihexyphenidy $14 \mathrm{mg} /$ day. Extra pyramidal symptomswere present and improved after adding trihexyphenidyl with no additional side effects of adding medication. Eosinophil count decreased to $20 \%$ at the time of discharge. The patient was discharged in satisfactory condition.

\section{DISCUSSION}

Eosinophilia, although a rare side effect associated with clozapine, has been reported in the literature with an incidence of 0.2 to $61.7 \%$ in clozapine-treated patients.10 Drug-induced eosinophilia has been defined as $>600 / \mathrm{mm}^{3}$ eosinophil counts in peripheral blood smear and hypereosinophiliawith a count of more than 1,500 eosinophils $/ \mathrm{mm} 3$ of blood. ${ }^{3}$ In most of the case reports it has been presented with organ-specific inflammation. ${ }^{4,9,11,12}$

Drug-induced eosinophilia is usually seen during the initial phase of treatment with clozapine, usually within first 4 weeks of therapy. ${ }^{3}$ In our patient, we further confirmed the association of eosinophilia induced by clozapine by applying Naranjo algorithm on which patient scored +5 thus confirming the co-relation $(+5$ score correspond to probable adverse drug reaction). ${ }^{13}$

The pathophysiology of clozapine-induced eosinophilia is unclear, but Lucht et al. hypothesized that Type I hypersensitivity reaction is involved in the etiology of clozapine-induced eosinophilia. ${ }^{14}$ This hypothesis has been supported by the evidence of raised $\operatorname{IgE}$ in a few case reports as well as depicted in our patient. The second hypothesis is stimulation of T lymphocyte and subsequent stimulation of IL-5 resulting in the raised levels of eosinophils. ${ }^{15}$

Clozapine-associated eosinophilia is understood in two different forms: first, transient benign eosinophilia and second eosinophilia with end-organ damage.

An important finding, in this case, was that eosinophilia occurred after re-introduction of clozapine. Mostly, if not all, the research available on clozapine-induced eosinophilia has been documented in patients who were prescribed clozapine for the first time.

Current guidelines regarding hematological monitoring lack specific emphasis on eosinophil count monitoring. However, the above case presentation emphasizes the fact that clinicians should give due importance to the eosinophil count while reviewing haemogram otherwise we might miss this rare but severe side effect.

Also, some case reports have speculated that in the absence of end-organ damage eosinophilia is usually benign and transient and clozapine can be continued safely after proper evaluation of the patient to rule out any end organ damage. ${ }^{16}$

This case report adds to existing literature that close monitoring is required in any patient receiving clozapine with a lookout on eosinophil count, even if the patient has displayed no such adverse effect in the past. It also strengthens the existing literature regarding the safety of continuation of clozapine in such cases where end-organ damage has been ruled out.

\section{REFERENCES}

1. Geller B, Luby JL, Joshi P, Wagner KD, Emslie G, Walkup JT, et al. A randomized controlled trial of risperidone, lithium, or divalproex sodium for initial treatment of bipolar I disorder, manic or mixed phase, in children and adolescents. Archives of general psychiatry. 2012 May 1;69(5):515-528.

2. Deliliers GL. Blood dyscrasias in clozapine-treated patients in Italy. Haematologica. 2000 Jan 1;85(3):233-237.

3. Hummer M, Sperner-Unterweger B, Kurz M, Fleischhacker WW, Falk M, Kemmler G, Oberbauer H. Does eosinophilia predict clozapine induced neutropenia?. Psychopharmacology. 1996 Mar 1;124(1-2):201-204.

4. Karmacharya R, Mino M, Pirl WF. Clozapine-induced eosinophilic colitis. American Journal of Psychiatry. $2005 \mathrm{Jul}$ 1;162(7):1386-1387.

5. Zipris P, Melamed Y, Weizman A, Bleich A. Clozapine-induced eosinophilia and switch to quetiapine in a patient with chronic schizophrenia with suicidal tendencies. Israel Journal of Psychiatry and Related Sciences. 2007 Jan 1;44(1):54-56.

6. Frankenburg F, Kando J. Eosinophilia, clozapine, and pancreatitis. The Lancet. 1992 Jul 25;340(8813):251.

7. Stricker BC, Tielens JA. Eosinophilia with clozapine. The Lancet. 1991 Dec 14;338(8781):1520-1521.

8. Tiihonen J, Paanila J. Eosinophilia associated with clozapine. The Lancet. 1992 Feb 22;339(8791):488.

9. Banov MD, Tohen M, Friedberg J. High risk of eosinophilia in women treated with clozapine. The Journal of clinical psychiatry. 1993 Dec;54(12):466-469.

10. Schuepbach D, Merlo MC, Kaeser L, Brenner HD. Successful challenge with clozapine in a history of eosinophilia. International clinical psychopharmacology. 1998 Jan;13(1): 33-37.

11. Elias TJ, Bannister KM, Clarkson AR, Faull D, Faull RJ. Clozapine-induced acute interstitial nephritis. The Lancet. 1999 Oct 2;354(9185):1180-1181. 
12. Merrill DB, Ahmari SE, Bradford JM, Lieberman JA. Myocarditis during clozapine treatment. American Journal of Psychiatry. 2006 Feb 1;163(2):204-208.

13. Naranjo CA, Busto U, Sellers EM, Sandor P, Ruiz I, Roberts EA, Janecek E, Domecq C, Greenblatt DJ. A method for estimating the probability of adverse drug reactions. Clinical Pharmacology \& Therapeutics. 1981 Aug 1;30(2):239-245.

14. Lucht MJ, Rietschel M. Clozapine-induced eosinophilia: subsequent neutropenia and corresponding allergic mecha- nisms. The Journal of clinical psychiatry. 1998 Apr;59(4): 195-197.

15. Thatcher GW, Cates M, Bair B. Clozapine-induced toxic hepatitis. The American journal of psychiatry. 1995 Feb;152: 296-297.

16. Aneja J, Sharma N, Mahajan S, Chakrabarti S, Grover S. Eosinophilia induced by clozapine: a report of two cases and review of the literature. Journal of family medicine and primary care. 2015 Jan;4(1):127-129. 